\title{
Microrefuges and the occurrence of thermal specialists: implications for wildlife persistence amidst changing temperatures
}

\author{
L. Embere Hall ${ }^{1 *}$ (D) Anna D. Chalfoun ${ }^{2}$, Erik A. Beever ${ }^{3,4}$ and Anne E. Loosen ${ }^{5}$
}

\begin{abstract}
Background: Contemporary climate change is affecting nearly all biomes, causing shifts in animal distributions, phenology, and persistence. Favorable microclimates may buffer organisms against rapid changes in climate, thereby allowing time for populations to adapt. The degree to which microclimates facilitate the local persistence of climate-sensitive species, however, is largely an open question. We addressed the importance of microrefuges in mammalian thermal specialists, using the American pika (Ochotona princeps) as a model organism. Pikas are sensitive to ambient temperatures, and are active year-round in the alpine where conditions are highly variable. We tested four hypotheses about the relationship between microrefuges and pika occurrence: 1) Local-habitat Hypothesis (local-habitat conditions are paramount, regardless of microrefuge); 2) Surface-temperature Hypothesis (surrounding temperatures, unmoderated by microrefuge, best predict occurrence); 3) Interstitial-temperature Hypothesis (temperatures within microrefuges best predict occurrence), and 4) Microrefuge Hypothesis (the degree to which microrefuges moderate the surrounding temperature facilitates occurrence, regardless of other habitat characteristics). We examined pika occurrence at 146 sites across an elevational gradient. We quantified pika presence, physiographic habitat characteristics and forage availability at each site, and deployed paired temperature loggers at a subset of sites to measure surface and subterranean temperatures.

Results: We found strong support for the Microrefuge Hypothesis. Pikas were more likely to occur at sites where the subsurface environment substantially moderated surface temperatures, especially during the warm season. Microrefugium was the strongest predictor of pika occurrence, independent of other critical habitat characteristics, such as forage availability.

Conclusions: By modulating surface temperatures, microrefuges may strongly influence where temperature-limited animals persist in rapidly warming environments. As climate change continues to manifest, efforts to understand the changing dynamics of animal-habitat relationships will be enhanced by considering the quality of microrefuges.
\end{abstract}

Keywords: Refuge, Global warming, Microclimate, Microhabitat, Mammal, Temperature-sensitive

\section{Background}

Environments across the globe are changing with unprecedented rapidity. In many cases, habitat cues no longer correspond with adaptive fitness outcomes [1], phenotypes are mismatched to current conditions [2], and resources are unavailable during critical developmental periods [3, 4]. Theory suggests that geographically restricted populations

\footnotetext{
* Correspondence: emberehall@gmail.com

${ }^{1}$ Wyoming Cooperative Fish and Wild life Research Unit, Department of Zoology and Physiology, University of Wyoming, 1000 E University Ave., Laramie, WY 82070, USA

Full list of author information is available at the end of the article
}

with low dispersal capability and long generation times may be particularly ill-equipped to cope with rapid environmental change, especially if the species is also a habitat specialist [5]. For these species, immediate responses, such as the use of microrefuges, may offer an instantaneous mechanism by which individuals can locally persist despite changing conditions. Yet, the role of many plastic responses and the habitat characteristics that facilitate them remain untested.

Climate change is a particularly pervasive form of rapid environmental change. Montane ecosystems, which occupy approximately $20 \%$ of the planet's land surface, may 
be particularly vulnerable to climate change [6]. The higher elevations of the northern Rocky Mountains, USA, for example, have experienced nearly three times the global average temperature increase over the past century, with an unprecedented decrease in snowpack $([7,8]$, but see [9]). Simultaneously, montane environments often support unique species assemblages and a high degree of endemism which can be disproportionately affected by warming [10-12].

Alpine mammals may provide valuable insights into animal responses to climate change, because they are often highly specialized, geographically restricted species, with relatively long generation times. This combination of characteristics likely limits the role of adaptive evolution in species persistence, emphasizing instead the importance of more immediate responses, such as behavioral plasticity and exploitation of favorable microhabitats [13-15].

\section{Microclimatic refuges}

Microrefuges provide enhanced resources compared with the surrounding habitat matrix, and can afford organisms protection from environmental stressors. Unlike refugia which may protect populations during prolonged periods (e.g. centuries) of inhospitable conditions, refuges operate within the life span of an organism [16, 17]. The importance of microrefuges for species distribution has been acknowledged for a long time (e.g., $[18,19])$. Despite this, relatively few species distribution models include microhabitat predictors in efforts to quantify future ranges [20]. As a result, the availability of microrefuges is often excluded from measurements that assess species' vulnerability to rapid environmental change [21]. Organisms can exploit microrefuges immediately to access favorable thermoclimatic profiles, foraging opportunities, nesting sites or shelter from extreme conditions [22-24]. In the case of temperature-sensitive species, individuals can exploit microhabitats that buffer otherwise stressful temperatures [23, 25, 26]. Microclimate data, coupled with species occurrence information, can therefore help elucidate connections between species persistence and the availability of microrefuges.

\section{American Pikas}

The American pika (Ochotona princeps), a species of broad conservation concern [27-29], is an ideal species through which to evaluate the importance of microrefuges. Pikas are sensitive to ambient temperatures [30, 31], with hyperthermia and death resulting after brief exposures to ambient temperatures $>28{ }^{\circ} \mathrm{C}$ [32]. Pikas can exploit favorable temperatures in interstitial spaces between rocks (hereafter talus), and are one of the only vertebrates active year-round in montane systems, where some of the most extreme climatic changes are occurring
[30, 31]. Additionally, pikas are habitat specialists with relatively low fecundity and dispersal capability [30, 32]. As a result, immediate responses to changing conditions may be essential to the species' persistence. Pikas also provide a rare opportunity to investigate climate change effects in the absence of physical habitat loss, because they live almost exclusively in relatively undisturbed talus habitats ([33]; but see [34]).

Although some populations of pikas have experienced climate-related range contractions [35] and extirpations as a result of climate change [31, 36, 37], these patterns are not consistent across the species' range [38-40]. Whereas low-elevation populations in the southern Great Basin recently have shown significant upslope range retractions in response to warming temperatures [36, 41], populations in the nearby eastern Sierra Nevada mountains persist despite marginal climatic conditions, atypical habitat and low-quality vegetation [42]. Population-level variation in climate sensitivity (how organisms interact with their climatic environment), exposure (how pronounced climate change is in a given site; [43, 44]) and adaptive capacity (ability of a species or associated populations to adjust to change; $[45,46])$ may explain some of the inconsistencies in range-wide responses. In addition, the availability of microrefuges at a local scale may shed light on fine-grain variation in patterns of persistence.

\section{Hypotheses and predictions}

We evaluated four alternative hypotheses about the relative influence of microrefuges on pika occurrence (Table 1). We anticipated that our hypotheses could manifest through two different temperature-based parameters: magnitude (mean value of a temperature parameter) and constancy (standard deviation of a temperature parameter). Consequently, three of our four hypotheses included predictions associated with both magnitude and constancy.

Table 1 Research hypotheses and corresponding model parameters

\begin{tabular}{ll}
\hline Hypothesis & Model parameters \\
\hline Local habitat & Best local-habitat model \\
Surface temperature (magnitude) & SurfTemp.mean + SurfTemp.mean ${ }^{2}$ \\
Surface temperature (variation) & SurfTemp.sd \\
Interstitial temperature (magnitude) & InterstitialTemp.mean \\
Interstitial temperature (variation) & InterstitialTemp.sd \\
Microrefuge (magnitude) & |TempDiff.mean| \\
Microrefuge (variation) & TempDiff.sd
\end{tabular}

Four alternative hypotheses about the relationship between American pika (Ochotona princeps) occurrence and microrefuges, and the corresponding model parameters. Three of our four hypotheses included predictions associated with both magnitude (mean value of a temperature parameter) and constancy (standard deviation of a temperature parameter). These hypotheses, consequently, appear twice 


\section{Local-habitat Hypothesis}

Local habitat conditions are paramount in predicting pika occurrence. Prediction: Slope, elevation, aspect and/or forage availability should best predict pika occurrence, regardless of microrefuges.

\section{Surface-temperature Hypothesis}

Talus-surface temperatures, unmoderated by microrefuge, best predict occurrence. Prediction 1 (magnitude): Pika occurrence should vary quadratically with mean daily surface temperature, such that the probability of occurrence is highest at intermediate temperatures. Prediction 2 (constancy): Pika occurrence should decrease with increasing variation in mean daily surface temperature.

\section{Interstitial-temperature Hypothesis}

Subsurface temperatures (temperatures in the talus interstices) best predict occurrence. Prediction 1 (magnitude): Pika occurrence should decrease with increasing mean daily interstitial temperature. Prediction 2 (constancy): Pika occurrence should decrease with increasing variation in mean daily interstitial temperature.

\section{Microrefuge Hypothesis}

The degree to which the subterranean environment moderates surface temperatures facilitates occurrence, regardless of other habitat characteristics. Prediction 1 (magnitude): Pika occurrence should be highest at sites where the subsurface temperature substantially buffers surface temperatures. Prediction 2 (constancy): Pika occurrence should be highest at sites where mean daily differences between the surface and subsurface temperatures is consistent.

\section{Methods}

\section{Study area}

We conducted our research in the central Rocky Mountains in the western United States. The project area was on the Bridger-Teton National Forest in Wyoming (centroid $43.4753^{\circ} \mathrm{N}, 110.7692^{\circ} \mathrm{W}$ ). The Bridger-Teton National Forest encompasses 1.4 million hectares and ranges in elevation from $1713-4211 \mathrm{~m}$. The majority (56\%) of precipitation falls during the cool season (October - March); average annual precipitation that falls as rain is $0.39 \mathrm{~m}$ [47]. January (average temperature $=-8{ }^{\circ} \mathrm{C}$ ) and July (average temperature $=17^{\circ} \mathrm{C}$ ) are typically the coldest and warmest months of the year, respectively. Our study sites occurred in coniferous forests, aspen parklands, subalpine and alpine communities. Dominant tree species included Douglas fir (Pseudotsuga menziesii), subalpine fir (Abies lasiocarpa), Engelmann spruce (Picea engelmannii), whitebark pine (Pinus albicaulis) and limber pine (Pinus flexilis).

\section{Site selection}

We used a probabilistic sampling design to create random survey locations. We generated sample points using a Generalized Random Tessellation Stratified (GRTS) sampling method [48-50]. The spatially-balanced GRTS design offered considerable flexibility over simple random and systematic designs, and allowed for sample sites to be added or removed as necessary without affecting selection probabilities and dispersion [48]. We constrained the sample frame to include potential pika habitat, proximity to trails $(<600 \mathrm{~m})$ and mountain slopes that were safe to travel $\left(\leq 35^{\circ} ;[50]\right)$. Habitat polygons were buffered by $12 \mathrm{~m}$ to exclude habitat edges [49]. Pikas are found almost exclusively in talus habitat [30]. Talus, however, is challenging to delineate from remotely sensed data, and was poorly represented in habitat-cover maps available for our study area [51]. Consequently, we extracted potential habitat from three map units that were closely associated with talus in our system: sparse vegetation, alpine vegetation and barren rock [51]. Prior to surveys, sample points were checked against aerial imagery to confirm that the point intersected talus habitat (sensu [50]). Plots were not sampled if they contained $<10 \%$ target habitat (talus, rock outcrops, creviced rock; $[49,50])$. All survey points were stratified by elevation (m): [1715-2344], [2345-2561], [2562-2778] and [2779-3702]. We used a stratified approach to ensure complete coverage of the elevational, climatic and habitat variability in our system. We generated 33 sample points and 33 oversample points (additional sample points to use if original points were unsuitable; [52]) per elevation stratum. We also selected 14 U.S. Forest Service pika-monitoring points that had been identified as part of an agency effort to quantify long-term population trends. These points were identified using the same GRTS-based sampling approach, but with only two elevation categories (low and high), rather than four.

\section{Occurrence surveys}

We surveyed sites during 24 June - 28 October, 2010 2012. A single technician completed a 30-minute occurrence survey at each plot $[49,50]$, except in cases of dual-observer surveys (see below). Surveys began with a 5-minute silent observation period. A single observer subsequently searched the plot for direct or indirect pika sign during the remainder of the survey period. Plots were considered occupied if direct or fresh indirect sign was detected. Indirect sign included visual detections of scat or fresh haypiles, and direct sign included visual or aural detection of pikas. Haypiles are caches of vegetation that pikas harvest during the summer months and primarily consume when green vegetation is no longer available [56]. We did not classify plots as occupied 
based only on fresh scat because of challenges in confidently ageing scat $[40,53]$ and the length of time that scat can persist in the environment [54].

Two observers conducted surveys at a subset of plots $(n=59)$ to estimate detection probabilities. The protocols described previously also were used in dualobserver surveys, except that each observer surveyed a site for 15 minutes, rather than 30 minutes. One observer surveyed a plot, followed immediately by the second observer. During each dual-observer survey, observers collected data independently and did not discuss observed sign.

We recorded wind speed $(\mathrm{kph})$ during each survey using a hand-held weather meter (2000 Pocket Wind Meter, KestrelMeters, Birmingham, MI) to determine the suitability of survey conditions. Surveys were not conducted in rain or in high winds (sustained wind speed $>25 \mathrm{kph}$ ), as these conditions could have influenced pika detections [55].

\section{Habitat characteristics Plot characteristics}

We recorded plot-level characteristics known to influence pika occurrence, including slope, aspect and elevation at each survey location $[40,49,50,56]$. Slope and aspect were measured at the center of each plot using a hand-held compass equipped with a clinometer. We calculated the elevation at the center of each plot from a 10-m digital elevation model of the entire study area.

Forage availability also may influence the likelihood that a plot is occupied [56], as pikas have high metabolic requirements, are active overwinter (i.e. do not hibernate), and hoard food resources for consumption during periods when green vegetation is unavailable $[50,57,58]$. We quantified forage resources at each site using a $100-\mathrm{m}$ line-point-intercept transect [59]. We established four, $25-\mathrm{m}$ transect lines separated by $90^{\circ}$. Each transect started at the plot center. We recorded all vegetation hits $\leq 0.50 \mathrm{~m}$ in height at each meter mark (1-25 m), for a total of 100 point-measurements per site. Vegetation hits above $0.50 \mathrm{~m}$ were considered inaccessible to pikas and were not included in our assessment. Both vascular (grasses, forbs, shrubs and trees) and non-vascular plants were included, as pikas also have been observed foraging on lichens and bryophytes [60-62]. We defined forage availability as the sum of all vegetation hits encountered along the four, 25-m transects.

\section{Surface temperatures and subsurface microrefuges}

We deployed 40 pairs of temperature sensors at a subset of survey sites. The sensors allowed us to quantify how much the subsurface environment differed from, and therefore buffered, surface temperatures. We randomly selected 10 sites in each of the four elevation categories as locations for temperature loggers. We placed iButtons (Maxim Integrated Products, model DS1921G, accuracy $\pm 1{ }^{\circ} \mathrm{C}, 0.5{ }^{\circ} \mathrm{C}$ increments) in water-tight containers ( $5 \mathrm{~g}$-jars made of clear plastic). Each jar contained a pinch of dessicant and was sealed with Teflon tape $[31,56]$. We deployed iButtons $<5 \mathrm{~m}$ from pika sign, or if sign was lacking, we placed iButtons near a prominent, overhanging rock closest to the plot center. Each iButton pair included a surface sensor and a subsurface sensor. Surface-temperature measurements were intended to reflect conditions that individuals experienced while on the surface of the talus, rather than ambient temperature. Consequently, the surface iButton was wired to a prominent north-facing rock, completely shaded from direct sun exposure. We suspended the subsurface iButton $0.5 \mathrm{~m}$ below the talus surface $[31,56,63]$, except in a few cases where the talus was $<0.5 \mathrm{~m}$ deep. In these cases, we suspended the logger a few centimeters above the ground beneath the talus. While this difference in deployment depth may have influenced the temperatures that were logged, it also allowed us to accurately characterize the habitat that was available to individuals at shallow-talus sites. Paired loggers were time-synchronized to record simultaneous temperature readings. Loggers recorded the temperature every 4 hours $(0200,0600,1000,1400,1800$, and 2200) for 341 days, or approximaely 11 months. We deployed loggers immediately following the occurrence survey at each site. Loggers deployed in one year were retrieved in the next year, when occurrence surveys were repeated. Occurrence data collected on the second visit to sites were used in analyses. These data allowed us to evaluate occurrence patterns that were most likely to result from conditions experienced during the temperature-sampling period.

\section{Statistical analyses \\ Detection probability}

Although pikas have a high probability of detection given presence [31, 49], we examined variation in detection probabilities as an initial step in model fitting. We used data from dual-observer surveys to estimate detection probabilities and probability of occupancy. We quantified detection probabilities using a simple single-season model where both detection and occupancy were held constant (program PRESENCE 7.3; [64]).

\section{Local habitat, surface temperature and subsurface microrefuge}

We used a two-step modelling approach to test our hypotheses. We suspected that local-habitat characteristics could influence the probability of pika occurrence independent of factors related to microrefuge, so we modeled them first using a suite of logistic-regression models with pika occurrence as the response (local-habitat models; GLM with a binomial link). Local-habitat variables included 
slope, aspect, elevation and forage availability. Each of the four variables have been shown to affect metrics of pika presence, density or abundance [38, 50, 56, 57, 65]. We used the cosine of aspect in our models, which characterized the northness of a site [66]. In addition to these linear effects, we considered a quadratic elevation term, as some studies have suggested an upper as well as a lower elevation limit for pikas $[50,56]$. We also considered an interaction between elevation and forage availability [56]. Our candidate model suite included nine models: a univariate model for each linear predictor (4 models); an additive model containing the three physiographic terms (slope, elevation, aspect); a quadratic elevation model; a model with an interaction between elevation and forage availability; an additive model containing all of the linear terms; and a global model.

Next we advanced the best-supported models (summed model probability $\geq 90 \%$ ) from the first model set into a second suite of eight candidate models (surface temperature, subsurface temperature and subsurfacemicrorefuge models). Due to a smaller sample, models in the second candidate suite included three or fewer predictors to reduce the potential of overfitting [67]. Each candidate model in the second set represented one of our hypotheses about the role of microrefuges as a predictor of pika occurrence (Table 1). We expected a nonlinear relationship between surface temperature and pika occurrence, so we included a quadratic effect of surface temperature in our models.

All temperature metrics reflected the average daily value at each site. We calculated average daily values for surface and subsurface temperatures by first determining the mean value for each sample-day at each site (derived from 6 readings/site/day). Then we averaged these values across the amount of time that the logger was deployed (approximately 11 months), resulting in 1 value per site. We quantified subsurface-microrefuge (the degree to which the talus environment moderated surface temperatures) as the absolute value of the mean daily difference between the surface and subsurface temperatures. We used the absolute difference rather than the actual difference because the absolute value allowed us to evaluate surface-condition moderation independent of season. We subtracted the subsurface temperature from the surface temperature; therefore differences were likely to be positive during the summer when the interstices were cooler than the surface, and negative in winter. These values were calculated by first determining the difference between surface and subsurface temperatures at each 4-hr sampling event. Next, we took the absolute value of these differences. Similar to the process for surface and subsurface temperatures, we next calculated the mean value for each sample-day at each site and averaged these values across the amount of time that the logger pair was deployed. While this approach lacks the temporal specificity to capture fine-scale variation in temperature, it allowed us to match the resolution of our temperature predictors with the annual-resolution of our speciesoccurrence information.

We expected that subsurface microrefuges could provide a critical buffer for pikas against high temperatures associated with the warm season during which pikas collect vegetation for overwinter caches. Consequently, we also investigated the relative importance of microrefuges during the period in which green vegetation was available. We calculated the dates of maximum rate of green-up and maximum rate of brown-down from a double-logistic curve fitted to Normalized Difference Vegetation Index data (from MOD09Q1 of MODIS terra satellite, 8-day $250 \mathrm{~m}$ resolution) [68]. We determined green up and brown down values for 9 representative sites which spanned the gradients of elevation, latitude and aspect in our study area. The values for each site were averaged to determine a single mean date of maximum green up and a single mean date of maximum brown down. The same temperature metrics were developed for our warm-season analysis as for our year-long assessment, except that subsurface microrefuge was represented by the difference between surface and subsurface temperatures, rather than by the absolute value of the difference. Since we did not anticipate an effect of snow cover during the warm season, the absolute value of the temperature difference was unnecessary. Average daily values reflected the period during which green vegetation was available, instead of the full duration of logger deployment.

Finally, to better understand the role of microrefuges in moderating high-temperature extremes, we conducted a post hoc analysis that examined temperature metrics at occupied and unoccupied sites during the warmest 7-day period of the study. We calculated mean temperature values for each 4-hour sampling event during the 7 days, grouped by occupancy status. We determined whether temperature metrics were different between occupied and unoccupied sites by examining overlap between bootstrapped, $95 \%$ confidence intervals (1000 model iterations).

The relative degree of model support was evaluated using Akaike's Information Criterion corrected for small sample sizes $\left(\mathrm{AIC}_{\mathrm{c}}\right)$, model probabilities and evidence ratios [69]. We computed AICc-related values using the $\mathrm{R}$ package AICcmodavg [70]. Goodness-of-fit of the bestsupported model was evaluated using the decile method $\left(X^{2} ;[71]\right)$. We evaluated goodness-of-fit for the bestsupported model because we used this model to make inferences about the effects of local-habitat characteristics and microrefuges on pika occurrence. While the decile method indicates whether a model fits, sensitivity and specificity provide a means to quantify model 
performance. Sensitivity refers to the proportion of points where the species was present that were also predicted by the model to have the species present. Similarly, specificity refers to the proportion of points that were correctly predicted as absences [71]. We used the $\mathrm{R}$ package ROCR to generate sensitivity and specificity values [72]. As an additional assessment of model performance, we calculated the area under the Receiver Operating Characteristic curve (hereafter AUC; [71]). We analyzed the AUC and the sensitivity and specificity of our top-ranked model to determine overall model performance. Effect sizes were evaluated using odds ratios and were calculated from the beta coefficients associated with individual variables [71].

To minimize problems with multicollinearity, we did not include strongly correlated variables (Pearson correlation coefficients $\geq 0.7$; [73]) in our models. All analyses were completed in $\mathrm{R}$ [74].

\section{Results}

\section{Detection and proportion of sites occupied}

We surveyed 146 sites, and recorded evidence of pika occurrence on 70 of the sites (48\%). Our detection probability was $0.82(95 \% \mathrm{CI}=0.61-0.93)$, resulting in a $10 \%$ increase in estimated site occupancy over the naïve estimate $(\widehat{\psi}=58 \%)$.

\section{Local-habitat}

Sample sites occurred along a wide range of elevation $(1750-3406 \mathrm{~m})$, slope $\left(0.5-45^{\circ}\right)$, aspect $\left(5-359^{\circ}\right)$ and forage availability $(0-108$ "hits"). Three models in our candidate set of nine local-habitat models received support, and were included in the $90 \%$ confidence set (Table 2; cumulative model probability $=0.94$ ). The top models included linear effects of slope, elevation and aspect. Based on the second-ranked model, which included all three physiographic terms, pikas were most likely to occur on northerly aspects (odds ratio $=1.97, \mathrm{CL}=1.24$, $3.19, P=0.005, \mathrm{df}=142)$. The individual effects of slope $(P=0.163, \mathrm{df}=142)$ and elevation $(P=0.498, \mathrm{df}=142)$ on pika occurrence were non-significant.

We advanced the first- and second-ranked models from our local-habitat analyses (cumulative model probability $=0.86$ ). While the third-ranked model was included in the $90 \%$ confidence set, it was not advanced because it had a notably lower model probability $\left(W_{\mathrm{j}}=0.08\right)$ and weight of evidence $\left(E_{\mathrm{i}}=7.9\right)$, compared to the other two.

\section{Surface temperature and subsurface microrefuge}

Of the 40 deployed logger pairs, two failed to record timesynchronized temperature data. Consequently, the sample size for all temperature-based analyses was 38 . We documented evidence of pika occurrence at $25(66 \%)$ of the sites equipped with loggers.

\section{Year-long patterns}

The second set of models evaluated support for our hypotheses about the importance of microrefuges. Three models were included in the $90 \%$ confidence set (Table 3; cumulative model probability $=0.90$ ). Two of the three models contained some measure of microrefuge. The magnitude of subsurface microrefuge (absolute value of the daily difference between the surface and subsurface temperatures) was the strongest predictor of pika occurrence $(\beta=2.89, P=0.038, \mathrm{df}=36)$, and the only significant predictor in the $90 \%$ confidence set. The top-ranked model included a univariate effect of microrefuge, had considerable support $\left(W_{\mathrm{j}}=0.81\right)$, and fit the data adequately $\left(x^{2}=4.93, P=0.553, \mathrm{df}=6\right)$. It had 11.6 times the weight of evidence relative to the next-ranked model. The top model also performed well, with sensitivity and specificity at $75 \%(c=0.60)$, and

Table 2 Rankings and relative support for local-habitat models that quantify pika occurrence

\begin{tabular}{llllll}
\hline Model & $K$ & $\mathrm{AlC}_{c}$ & $\Delta \mathrm{AlC}_{\mathrm{c}}$ & $W_{\mathrm{j}}$ & $E_{\mathrm{j}}$ \\
\hline Cos(Aspect) & 2 & 197.26 & 0.00 & 0.63 & $\mathrm{n} / \mathrm{a}$ \\
Slope + Elevation + Cos(Aspect) & 4 & 199.29 & 2.03 & 0.23 & 2.74 \\
Slope + Elevation + Cos(Aspect) + Forage & 5 & 201.42 & 4.16 & 0.08 & 7.88 \\
Slope & 2 & 204.06 & 6.80 & 0.02 & 31.50 \\
Global model & 7 & 204.56 & 7.30 & 0.02 & 31.50 \\
Elevation & 2 & 205.98 & 8.71 & 0.01 & 63.00 \\
Forage & 2 & 206.23 & 10.97 & 0.01 & 0.00 \\
Elevation (quadratic) & 3 & 207.52 & 11.85 & 0.00 & undefined \\
Elevation x Forage & 4 & 209.12 & undefined \\
\hline
\end{tabular}

Model-selection parameters from competing models used to explain the effects of local-habitat parameters on American pika (Ochotona princeps) occurrence in western Wyoming, USA, June - October, 2010 - 2012; K, number of parameters in the model; AIC $c_{c}$ Akaike Information Criterion corrected for small samples; $\triangle \mathrm{AIC}_{\mathrm{c}}$, difference for model relative to the smallest $\mathrm{AIC}_{\mathrm{c}}$ in the model set; $W_{\mathrm{j}}$, Akaike weight is the approximate probability in favor of the given model from the set of models considered; $E_{\mathrm{j}}$ represents the weight of evidence in support of a model, compared to the top ranked model ( $\left.W_{\mathrm{j} \text { Top }} / W_{\mathrm{ji}}\right)$ 
Table 3 Rankings and relative support for models that quantify the role of microrefuges in pika occurrence

\begin{tabular}{|c|c|c|c|c|c|}
\hline Model & K & $\mathrm{AlC}_{\mathrm{c}}$ & $\Delta \mathrm{AlC}_{\mathrm{c}}$ & $W_{\mathrm{j}}$ & $E_{\mathrm{j}}$ \\
\hline Subsurface microrefuge (magnitude) & 2 & 45.65 & 0.00 & 0.81 & $\mathrm{n} / \mathrm{a}$ \\
\hline Interstitial temperature (variation) & 2 & 50.52 & 4.87 & 0.07 & 11.60 \\
\hline Subsurface microrefuge (variation) & 2 & 52.55 & 6.90 & 0.03 & 27.00 \\
\hline Surface temperature (magnitude) & 3 & 52.56 & 6.91 & 0.03 & 27.00 \\
\hline Interstitial temperature (magnitude) & 2 & 52.82 & 7.18 & 0.02 & 40.50 \\
\hline Local habitat - Cos(Aspect) & 2 & 52.89 & 7.24 & 0.02 & 40.50 \\
\hline Surface temperature (variation) & 2 & 53.16 & 7.51 & 0.02 & 40.50 \\
\hline Local habitat - Slope + Elevation + Cos(Aspect) & 4 & 55.81 & 10.16 & 0.01 & 81.00 \\
\hline
\end{tabular}

Model-selection parameters from competing models used to examine the effects of microrefuges and surface temperatures on American pika (Ochotona princeps)

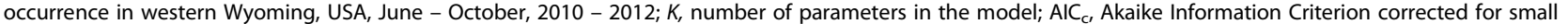
samples; $\triangle \mathrm{AlC}_{\mathrm{c}}$, difference for model relative to the smallest $\mathrm{AIC}_{\mathrm{c}}$ in the model set; $W_{\mathrm{j}}$, Akaike weight is the approximate probability in favor of the given model from the set of models considered; $E_{\mathrm{j}}$ represents the weight of evidence in support of a model, compared to the top ranked model ( $W_{\mathrm{j} \text { Top }} / W_{\mathrm{ji}}$ )

AUC $=0.72$. AUC values $0.7-0.8$ suggest acceptable discrimination between presences and absences [71]. Based on the top model, the odds of pika occurrence increased 17.9 times for each degree increase in the difference between the surface and subsurface temperature $(\mathrm{CL}=1.17,273.30, P=0.038, \mathrm{df}=36$; Fig. 1$)$.

Overall, habitat predictors received relatively little support, compared to temperature-based models. A univariate effect of aspect was the top-ranked model in our first candidate set $\left(W_{\mathrm{j}}=0.63\right)$, but placed near the bottom $\left(E_{\text {aspect }}=40.5\right)$ when competing with models that accounted for temperature metrics. Similarly, an additive model containing slope, elevation and aspect had some

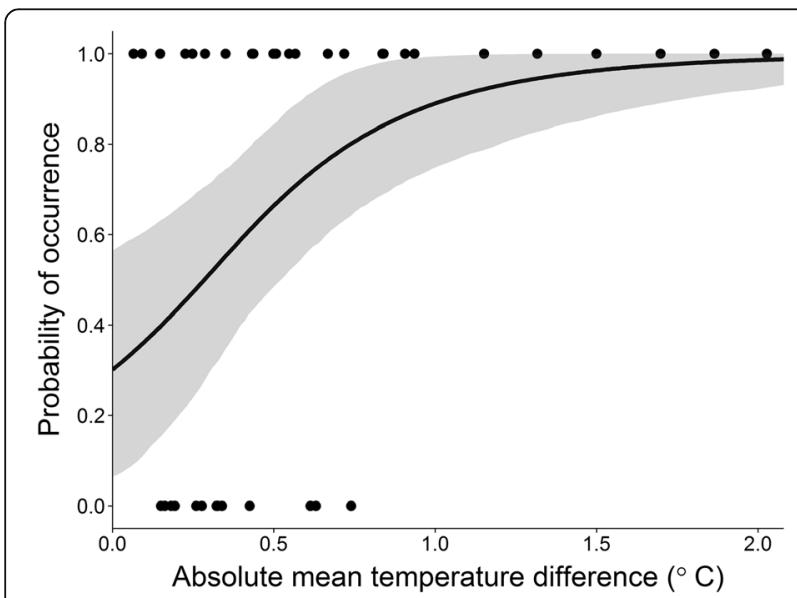

Fig. 1 Microrefuge and the predicted probability of pika occurrence. Predicted probability of American pika (Ochotona princeps) occurrence as a function of subsurface microrefuge (absolute value of the mean daily difference between surface and subsurface temperatures) in the central Rocky Mountains in the western United States, June - October, 2010 - 2012. Black dots represent observed occurrence data. Solid black line shows predicted values. Shaded band reflects non-parametric, bootstrapped $95 \%$ confidence intervals (1000 model iterations) for predicted values support in our first model set $\left(W_{\mathrm{j}}=0.23\right)$. It ranked last, however, when compared with temperature-based models $\left(W_{\mathrm{j}}=0.01\right)$.

\section{Warm-season patterns}

The mean date of maximum green up was 29 May $(\mathrm{SD}=15.3 \mathrm{~d})$. The mean date of maximum brown down was 5 October $(\mathrm{SD}=8.4 \mathrm{~d})$. Given the imprecision associated with our estimates, we simplified the warm season to 1 June - 30 September. This period included the warmest four months in our study area. It also corresponded to peaks in both grazing and haying activity documented in two populations of American pikas elsewhere in the Rocky Mountains [72].

We assessed the same suite of 8 models for the warm season to evaluate the relative importance of microrefuges during the period during which green vegetation was available (Table 4). Similar to the year-long results, the top-ranked model included a significant, univariate effect of subsurface microrefuge $(\beta=0.702, P=0.02$, $\mathrm{df}=36)$, and received reasonable support $\left(\mathrm{W}_{\mathrm{j}}=0.75\right)$. Two models were included in the $90 \%$ confidence set. The subsurface microrefuge model had 5.4 times the weight of evidence relative to the next-ranked model and 37.5 times the weight of evidence compared to the highest-ranked local-habitat model. A univariate effect of the variation within the talus interstices ranked immediately below the subsurface microrefuge model, but received considerably less support $\left(\mathrm{W}_{\mathrm{j}}=0.14\right)$.

The warmest 7-day period during the study was 22 July - 29 July, 2011. Interstitial temperatures at occupied sites were cooler than unoccupied sites, both on average $\left(5.06 \mathrm{C}^{\circ}\right.$ cooler, $\left.\mathrm{SD}=1.84 \mathrm{C}^{\circ}\right)$ and at nearly every 4-hour sampling event in the 7-day period (Fig. 2). In addition, unoccupied sites tended to maintain heat within the interstices, resulting in warmer nocturnal conditions compared to occupied sites (Figs. 2 and 3). Occupied sites 
Table 4 Rankings and relative support for models that quantify the role of microrefuges in pika occurrence during the period in which green vegetation was available (1 June - 30 September)

\begin{tabular}{|c|c|c|c|c|c|}
\hline Model & K & $\mathrm{AlC}_{\mathrm{c}}$ & $\Delta \mathrm{AlC}_{\mathrm{c}}$ & $W_{j}$ & $E_{j}$ \\
\hline Subsurface microrefuge (magnitude) & 2 & 45.57 & 0.00 & 0.75 & $\mathrm{n} / \mathrm{a}$ \\
\hline Interstitial temperature (variation) & 2 & 48.95 & 3.38 & 0.14 & 5.36 \\
\hline Interstitial temperature (magnitude) & 2 & 51.78 & 6.22 & 0.03 & 25.00 \\
\hline Subsurface microrefuge (variation) & 2 & 52.51 & 6.94 & 0.02 & 37.50 \\
\hline Local habitat - Cos(Aspect) & 2 & 52.89 & 7.32 & 0.02 & 37.50 \\
\hline Surface temperature (variation) & 2 & 52.91 & 7.34 & 0.02 & 37.50 \\
\hline Surface temperature (magnitude) & 3 & 54.23 & 8.66 & 0.01 & 75.00 \\
\hline Local habitat - Slope + Elevation + Cos(Aspect) & 4 & 55.81 & 10.24 & 0.00 & unde \\
\hline
\end{tabular}

Model-selection parameters from competing models used to examine the effects of microrefuges and surface temperatures on American pika (Ochotona princeps) occurrence in western Wyoming, USA, 1 June - 30 September; $\mathrm{K}$, number of parameters in the model; AIC $C_{c}$ Akaike Information Criterion corrected for small samples; $\Delta$ $\mathrm{AIC}_{\mathrm{c}}$, difference for model relative to the smallest $\mathrm{AIC}_{\mathrm{c}}$ in the model set; $\mathrm{W}_{\mathrm{j}}$, Akaike weight is the approximate probability in favor of the given model from the set of models considered; $E_{j}$ represents the weight of evidence in support of a model, compared to the top ranked model $\left(W_{j}\right.$ Top $\left./ W_{j i}\right)$

were better buffered from diurnal surface-conditions (1000-1800 hours; occupied sites, mean temperature difference $=9.08 \mathrm{C}^{\circ}, \mathrm{SD}=1.88 \mathrm{C}^{\circ}$; unoccupied sites, mean temperature difference $=8.03 \mathrm{C}^{\circ}, \mathrm{SD}=2.17 \mathrm{C}^{\circ}$ ), though this difference was equivocal (Fig. 3 ).

\section{Discussion}

Microrefuges may help to buffer climate-sensitive species against temperature changes in warming environments [21, 75]. Our research provides evidence that the quality of microrefuges may be essential to the occurrence of mammalian thermal specialists, especially in ecosystems where temperatures are highly variable, such

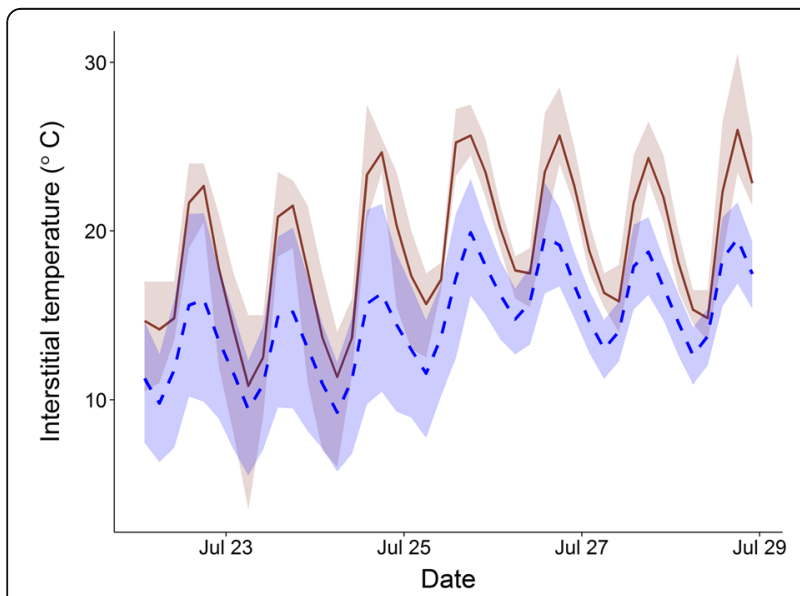

Fig. 2 Observed interstitial temperatures at occupied and unoccupied sites (warmest 7-day period of the study). Mean interstitial temperatures at sites that were occupied (dashed, blue line) and unoccupied (brown, solid line) by American Pika (Ochotona princeps) in the central Rocky Mountains during the warmest 7-day period of the study (22 July - 29 July). Peaks correspond to the warmest period of the day; troughs to the coolest. The shaded ribbons reflect bootstrapped, $95 \%$ confidence intervals (1000 model iterations) as in the alpine. Importantly, our work connects finescale, in-situ measurements of both the mean and the variability in microrefuge temperatures with species occurrence. Although other studies have quantified the extent to which microhabitats buffer ambient conditions $[21,23,25,76]$, comparatively few have evaluated the difference between the temperatures that an organism experiences in the surrounding territory (e.g., rock-surface conditions) and the operative conditions within available microrefuges. Even fewer have linked this difference to empirical species-occurrence information (but see [26]).

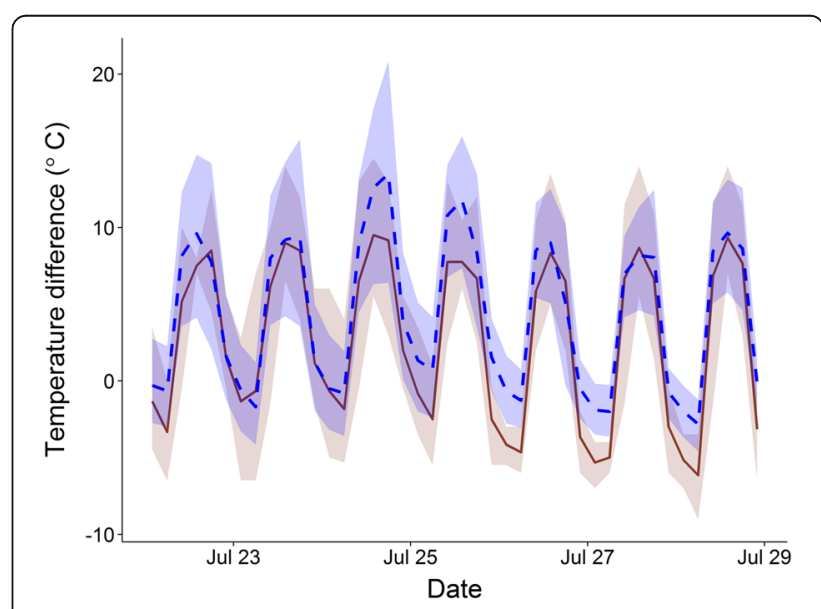

Fig. 3 Observed microrefuge temperatures at occupied and unoccupied sites (warmest 7-day period of the study). Mean differences between surface and subsurface temperatures at sites that were occupied (dashed, blue line) and unoccupied (brown, solid line) by American Pika (Ochotona princeps) in the central Rocky Mountains during the warmest 7-day period of the study (22 July - 29 July). Positive values indicate that the subsurface environment was cooler than surface conditions; negative values that the subsurface environment was warmer. Peaks correspond to the warmest period of the day; troughs to the coolest. The shaded ribbons reflect bootstrapped, $95 \%$ confidence intervals (1000 model iterations) 
Similar to caves and subterranean burrows, talus habitats provide non-living refuges to animals. Living microhabitats (e.g., ground vegetation) are more impacted by novel climates and, therefore, may provide less stable refuges compared to a non-living resource, such as talus [23].

We found robust support for our Microrefuge Hypothesis. The mean daily difference between surface and subsurface temperatures was the single-best predictor of pika occurrence. This result was particularly evident during the warm season, when green vegetation was available and pikas are most active on the surface of the talus (Fig. 4). Pikas were more likely to occur at sites where the subsurface environment substantially moderated surface temperatures, regardless of local-habitat characteristics or surface temperatures. The Interstitialtemperature Hypothesis received comparatively little support, indicating that the temperature within talus interstices alone was not sufficient to explain variation in pika occurrence. Relatively poor support for the Interstitialtemperature Hypothesis, coupled with strong support for the Microrefuge Hypothesis, especially during the warm season, suggests that microrefuges may shelter pikas from stressful surface conditions while simultaneously allowing access to resource benefits associated with particularly warm surface temperatures. Sites with warm mean daily surface temperatures, for example, are likely to experience earlier spring snowmelt, which provides earlier access to high-quality forage $[77,78]$. Variation in dates of parturition and initiation of first litters, moreover, has been positively correlated with snowmelt in North American pikas (O. princeps and O. collaris; [79-81]). Additionally, sites that provide a substantial gradient between surface and

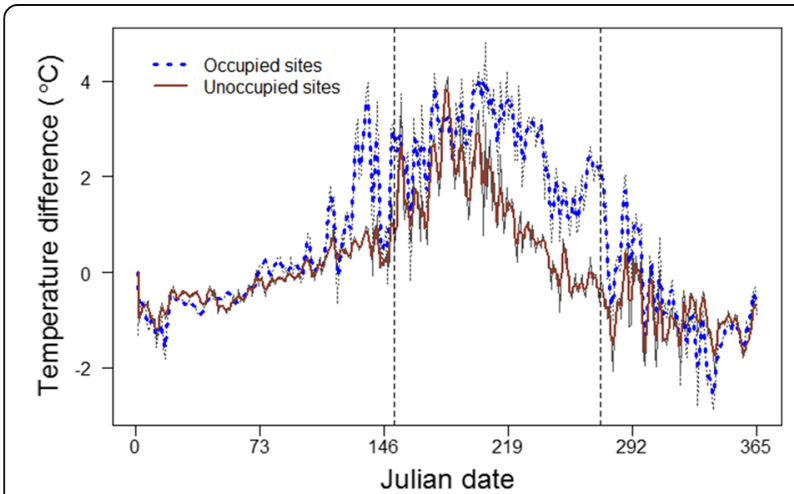

Fig. 4 Observed microrefuge temperatures at occupied and unoccupied sites (year-long). The observed differences between surface and subsurface temperatures at sites that were occupied and unoccupied by American Pika (Ochotona princeps) in the central Rocky Mountains, June - October 2010 - 2012. Data are summarized by Julian date, years averaged, and fit with a 3-day moving average. Two vertical, dashed lines denote the beginning and end of the warm season (1 June, 30 September, respectively), during which green vegetation was available, and pikas were collecting vegetation for overwinter food stores subsurface temperatures may allow individuals to shed heat quickly, thereby facilitating rapid cooling during particularly warm periods. Cape ground squirrels (Xerus inauris), for example, frequently retreat to subterranean burrows during periods of high solar insulation, thereby moderating body temperature and quickly dissipating heat load [82].

During the warmest 7-day period of the study, belowtalus temperatures were generally cooler than surface temperatures in the hottest parts of the day (1400-1800 hours), and warmer than surface conditions during the coldest (0200-0600 hours; Fig. 3). This is similar to findings by Henry et al. 2012, which showed that subsurface temperatures at pika-occupied sites were lower during the afternoon, and higher in the morning and night, compared to above-talus conditions [83]. The increased degree of temperature moderation at occupied sites likely provided animals with enhanced opportunities for rapid cooling, as well as greater protection from potentially stressful conditions.

The maximum mean daily difference between surface and subsurface temperatures was $2.0 \mathrm{C}^{\circ}$ over the duration of the sampling period (Fig. 1) and $5.6 \mathrm{C}^{\circ}$ during the warm season (Fig. 4). While these differences may seem small, a magnitude of even $2 \mathrm{C}^{\circ}$ reflects consistent modulation of surface-temperature extremes. The instantaneous difference between the surface and subsurface environment routinely exceeded $20 \mathrm{C}^{\circ}$ at some sites. Pikas maintain a high resting body temperature $\left(\bar{x}=40.1{ }^{\circ} \mathrm{C}\right)$ and a relatively low upper lethal temperature $\left(\bar{x}=43.1{ }^{\circ} \mathrm{C}\right.$; $\left.[30,84]\right)$. Endothermic animals compensate for ambient temperatures that exceed their upper critical temperature (UCT) by increasing metabolism [85], or by taking advantage of convective/conductive heat loss. Even a few degrees of surface-temperature moderation may protect pikas from costly shifts in metabolism, as long as refuge temperatures remain below the UCT.

The subsurface temperatures that we observed during the warm season $\left(\bar{x}=12.69{ }^{\circ} \mathrm{C}, \mathrm{SD}=5.39 \mathrm{C}^{\circ}\right.$; range $-2{ }^{\circ} \mathrm{C}-$ $21.94{ }^{\circ} \mathrm{C}$ ) were comparable to other studies across the species' range. Similarly, the average subsurface temperature during the summer in the southern Rocky Mountains was $10.6{ }^{\circ} \mathrm{C}\left(\mathrm{SD}=2.9 \mathrm{C}^{\circ}\right)[86]$; and $12.40{ }^{\circ} \mathrm{C}\left(\mathrm{SD}=1.00 \mathrm{C}^{\circ}\right)$ at pika-extant sites and $17.05{ }^{\circ} \mathrm{C}\left(\mathrm{SD}=0.81 \mathrm{C}^{\circ}\right)$ at pikaextirpated sites in the hydrographic Great Basin [31]. Lower mean interstitial temperatures were recorded in the Columbia River Gorge [21], though this is likely due to the temperature-buffering effects of moss cover prevalent on the surface of the talus, as well as topographical forcings that moderate temperatures in the gorge [21, 87].

Macrohabitat temperatures and biotic habitat characteristics may also influence the importance of microrefuges. For example, microrefuges might be especially important to pika occurrence where surface temperatures exceed 
physiological tolerances for prolonged periods. Surrounding vegetation can buffer interstitial temperatures through shading or through increased albedo [21]. Similarly, rockice features or subsurface water can influence microrefuge temperatures $[38,76]$. Subsequent studies with sufficient sample sizes to fit a context-dependent model could provide useful insights on the merits of this hypothesis.

We found little support for our Local-habitat Hypothesis. Pika occurrence was positively associated with steeper slopes and northerly aspects, however, the effects of these local-habitat characteristics were relatively unimportant compared with effects of subsurface microrefuges. We expected pika occurrence to be positively associated with both forage availability $[49,56,57]$ and elevation $[36,50]$. However, there was little support for either term in our models. Compared with more arid parts of the species' range, our study sites received relatively high annual precipitation. Consequently, pika populations in our system may be limited less by access to vegetation, compared with dryer areas containing lower plant biomass. The average forage availability at unoccupied sites was only 0.19 vegetation 'hits' less than occupied sites. Although individual pikas have unique diet-selection criteria [88], as a species they are generalist herbivores capable of consuming a variety of graminoids, forbs and bryophytes [61, 62]. Our measure of forage availability, however, did not address either vegetation diversity or the ratio of forbs: graminoids, both of which have been closely linked with metrics of pika population density elsewhere in the species' range [86]. Given comparable forage availability across study sites, and relatively flexible diets, forage likely did not constrain pika occurrence in our system.

Elevation has been linked to pika-abundance indices across the range of the species $[49,50,56]$, however, elevation itself likely does not limit pika distribution. Rather, elevation indexes relevant biological parameters that affect persistence. We directly measured the parameters that often are indexed by elevation, such as forage availability and temperature. Temperature metrics were more predictive of pika occurrence than elevation, which only indirectly reflected variation in climate conditions. Efforts both to understand current pika distribution, and to forecast future pika persistence under warming scenarios will be improved by incorporating in-situ temperature measurements [21], rather than surrogate variables such as elevation.

Microrefuges have the potential to buffer temperaturesensitive species against warming temperature trends $[21,26,43]$. They are not, however, a one-size-fits-all solution to facilitate species persistence. Use of microclimates can be costly, for example, if organisms shelter at the expense of other essential activities, such as foraging [22]. In addition, not all species have the behavioral capacity to capitalize on favorable microrefuges (e.g. [89]). If organisms are unable to take advantage of microrefuges, or if exploitation of microclimates inhibits essential processes, then reduced fitness ultimately will lead to extirpation. Species that can modulate behaviors to counter temperature extremes often are better able to exploit beneficial microenvironments. American pikas are capable of proximately adjusting to temperature variation through changes in body shape [33], food cache placement [62] and sheltering [34]. The degree to which behavioral flexibility, in combination with acclimatization and developmental plasticity [85], will facilitate the persistence of pikas and other animals in rapidly warming environments merits additional research.

Warming climate conditions have caused changes in the occurrence, abundance, morphology and phenology of species across the globe $[3,4]$. The magnitude of these changes, however, is inconsistent among clades, biogeographic regions or even within subpopulations of the same species. Some of this variation may be attributable to finescale differences in microclimatic conditions [44]. Broadscale temperature changes do not inherently produce the same magnitude of change at finer spatial scales [20]. Our understanding of species' responses to changing climate dynamics will be substantially improved by quantifying the relationships between broad-scale temperature increases and microclimatic variation. One of the simplest steps towards this understanding is to measure climate parameters on scales that are relevant to the organisms under study [20,90], including quantifying climate conditions associated with microrefuges.

\section{Conclusions}

Our work provides clear evidence that microrefuges are essential to the occurrence of a mammalian thermal specialist. Models of future climate indicate marked increases not only in average temperature values, but also in variation around the means [90]. In an increasingly unpredictable environment, microrefuges may provide organisms with a critical buffer against otherwise intolerable extremes. Consequently, microrefuges likely will influence where and the degree to which temperaturelimited animals can persist in warming environments.

\section{Acknowledgements \\ We are grateful to T. Robinson, J. Ceradini and J. Carlisle for advice on statistical analyses. Field and data support were provided by: S. Albeke, A. Byrd, A. Courtemanch, V. Gobrecht, S. Johnson, M. Karp, S. Kilpatrick, M. Merigliano, C. Schneebeck, D. Smith and J. Welz. We thank J. Merkle for support in calculating green-up and brown-down dates. Earlier versions of this manuscript were improved by K. Monteith, H. Lanier, two anonymous reviewers, and by colleagues in the Writing and Reviewing Science course at the University of Wyoming. Any use of trade, firm or product names is for descriptive purposes only and does not imply endorsement by the U.S. Government.}

\section{Funding}

Wyoming Governor's Big Game License Coalition, Wyoming Wildlife - The Foundation, $1 \%$ for the Tetons, Teton Science Schools, Bridger-Teton National Forest, Wyoming Game and Fish Department and Ralph \& Louise Haberfeld funded this research. 


\section{Availability of data and materials}

Data are available from LEH upon request. American pika are a Tier II Species of Greatest Conservation Need in Wyoming, and were recently petitioned to be listed as a threatened or endangered species under the Endangered Species Act. Consequently, location-associated information is deemed sensitive.

\section{Authors' contributions}

LEH formulated the idea for the study. LEH and ADC developed the hypotheses. LEH, EAB and AEL designed the research methodologies. AEL and LEH collected field data. LEH completed the statistical analyses and drafted the manuscript. ADC, EAB and AEL provided substantial conceptual and editorial advice. All authors read and approved the final manuscript.

\section{Competing interests}

The authors declare that they have no competing interests.

\section{Consent for publication}

Not applicable.

\section{Ethics approval and consent to participate}

All applicable institutional and national guidelines for the care and use of animals were followed. All research activities were conducted in accordance with U.S. Forest Service permit number 65203.

\section{Author details}

${ }^{1}$ Wyoming Cooperative Fish and Wild life Research Unit, Department of Zoology and Physiology, University of Wyoming, 1000 E University Ave., Laramie, WY 82070, USA. ${ }^{2}$ U.S. Geological Survey, Wyoming Cooperative Fish and Wildlife Research Unit, Department of Zoology and Physiology, University of Wyoming, 1000 E University Ave., Laramie, WY 82070, USA. ${ }^{3}$ U.S. Geological Survey, Northern Rocky Mountain Science Center, 2327 University Ave., Ste. 2, Bozeman, MT 59715, USA. ${ }^{4}$ Department of Biology, Montana State University, P.O. Box 173460, Bozeman MT 59717, USA. ${ }^{5}$ CW405 Department of Biological Sciences, University of Alberta, Edmonton T6G 2E9, $\mathrm{AB}$, Canada.

Received: 24 May 2016 Accepted: 30 August 2016

\section{Published online: 19 October 2016}

\section{References}

1. Robertson BA, Rehage JS, Sih A. Ecological novelty and the emergence of evolutionary traps. Trends Ecol Evol. 2013;28:552-60.

2. Mills LS, Zimova M, Oyler J, Running S, Abatzoglou JT, Lukacs PM. Camouflage mismatch in seasonal coat color due to decreased snow duration. Proc Natl Acad Sci. 2013;110:7360-5.

3. Parmesan C. Ecological and evolutionary responses to recent climate change. Annu Rev Ecol Evol Syst. 2006;37:637-69.

4. Walther G-R, Post E, Convey P, Menzel A, Parmesank C, Beebee TJC, et al. Ecological responses to recent climate change. Nature. 2002;416:389-96.

5. Roff D. The Evolution of Life History Traits. London: Chapman and Hall; 1992.

6. Gottfried M, Pauli H, Futschik A, Akhalkatsi M, Barančok P, Benito Alonso JL, et al. Continent-wide response of mountain vegetation to climate change. Nat Clim Chang. 2012;2:111-5.

7. Pederson GT, Gray ST, Woodhouse CA, Betancourt JL, Fagre DB, Littell JS, et al. The unusual nature of recent snowpack declines in the North American cordillera. Science. 2011;333:332-5.

8. Shuman B. Recent Wyoming temperature trends, their drivers, and impacts in a 14,000-year context. Clim. Change. 2012;112:429-47.

9. Oyler J, Dobrowski SZ, Ballantyne A, Klene A, Running S. Artificial amplification of warming trends across the mountains of the western United States. Geophys Res Lett. 2015;42:153-61.

10. Thuiller W, Lavorel S, Araújo MB, Sykes MT, Prentice IC. Climate change threats to plant diversity in Europe. Proc Natl Acad Sci U S A. 2005;102:8245-50.

11. Dirnböck T, Essl F, Rabitsch W. Disproportional risk for habitat loss of high-altitude endemic species under climate change. Glob Chang Biol. 2011:17:990-6.

12. Ohlemüller R, Anderson BJ, Araújo MB, Butchart SHM, Kudrna O, Ridgely RS, et al. The coincidence of climatic and species rarity: high risk to small-range species from climate change. Biol Lett. 2008;4:568-72.
13. Tuomainen U, Candolin U. Behavioural responses to human-induced environmental change. Biol Rev. 2011;86:640-57.

14. Van Buskirk J. Behavioural plasticity and environmental change. In: Candolin U, Wong B, editors. Behav. Responses to a Chang. World. 1st ed. Oxford: Oxford University Press; 2012. p. 145-58.

15. Morelli TL, Smith AB, Kastely CR, Mastroserio I, Moritz C, Beissinger SR. Anthropogenic refugia ameliorate the severe climate-related decline of a montane mammal along its trailing edge. Proc R Soc B Biol Sci. 2012;279:4279-86

16. Keppel G, Wardell-Johnson GW. Refugia: Keys to climate change management. Glob Chang Biol. 2012;18:2389-91.

17. Hannah L, Flint L, Syphard AD, Moritz MA, Buckley LB, McCullough IM. Finegrain modeling of species' response to climate change: Holdouts, steppingstones, and microrefugia. Trends Ecol Evol. 2014;29:390-7.

18. Grinnell J. The niche-relationships of the California Thrasher. Auk. 1917;34:427-33.

19. Hutchinson GE. Concluding remarks. Popul. Stud. Anim. Ecol. Demogr. Cold Spring Harb. Symp. Quant. Biol. 1957;22:415-27.

20. Potter KA, Woods HA, Pincebourde S. Microclimatic challenges in global change biology. Glob Chang Biol Biol. 2013;19:2932-9.

21. Varner J, Dearing MD. The importance of biologically relevant microclimates in habitat suitability assessments. PLoS One. 2014;9, e104648.

22. Dias $N$, Hassall $M$, Waite $T$. The influence of microclimate on foraging and sheltering behaviours of terrestrial isopods: Implications for soil carbon dynamics under climate change. Pedobiologia. 2012;55:137-44.

23. Scheffers B, Edwards D, Diesmos A, Williams SE, Evans T. Microhabitats reduce animal's exposure to climate extremes. Glob Chang Biol. 2014;20:495-503.

24. Sinclair BJ, Vernon P, Jaco Klok C, Chown SL. Insects at low temperatures: an ecological perspective. Trends Ecol Evol. 2003;18:257-62.

25. Shoo LP, Storlie C, Williams YM, Williams SE. Potential for mountaintop boulder fields to buffer species against extreme heat stress under climate change. Int J Biometeorol. 2010;54:475-8.

26. Shi H, Paull D, Wen Z, Broome L. Thermal buffering effect of alpine boulder field microhabitats in Australia: Implications for habitat management and conservation. Austral Ecol. 2015;40:528-36.

27. US Fish and Wildlife Service. Endangered and threatened wildlife and plants; 12-month finding on a petition to list the American pika as threatened or endangered. 2010. West Valley City.

28. Krajick K. All downhill from here? Science. 2004;303:1600-2.

29. Smith AT, Weidong L, Hik DS. Pikas as harbingers of global warming. Species. 2004;41:4-5.

30. Smith A, Weston M. Ochotona princeps. Mamm Species. 1990;1-8.

31. Beever E, Ray C, Mote PW, Wilkening JL. Testing alternative models of climate-mediated extirpations. Ecol Appl. 2010;20:164-78.

32. Henry P, Sim Z, Russello MA. Genetic evidence for restricted dispersal along continuous altitudinal gradients in a climate change-sensitive mammal: The American Pika. PLoS One. 2012;7:1-10.

33. Ray C, Beever E, Loarie SR. Retreat of the American pika: Up the mountain or into the void? In: Brodie JF, Post E, Doak DF, editors. Wildl. Conserv. a Chang. Clim. First. Chicago and London: The University of Chicago Press; 2013. p. $245-70$

34. Smith AT. The distribution and dispersal of pikas : Influences of behavior and climate. Ecology. 1974;55:1368-76.

35. Moritz C, Patton JL, Conroy CJ, Parra JL, White GC, Beissinger SR. Impact of a century of climate change on small-mammal communities in Yosemite National Park, USA. Science. 2008;322:261-4.

36. Beever E, Ray C, Wilkening J, Brussard P, Mote P. Contemporary climate change alters the pace and drivers of extinction. Glob Chang Biol. 2011;17:2054-70.

37. Stewart JAE, Perrine JD, Nichols LB, James H, Millar Cl, Goehring KE, et al. Revisiting the past to foretell the future: summer temperature and habitat area predict pika extirpations in California. J Biogeogr. 2015;42:880-90.

38. Millar Cl, Westfall RD. Distribution and climatic relationships of the American Pika (Ochotona princeps) in the Sierra Nevada and Western Great Basin, U.S.A.; Periglacial landforms as refugia in warming climates. Arctic, Antarct Alp Res. 2010;42:76-88.

39. Collins GH, Bauman BT. Distribution of low-elevation American pika populations in the northern Great Basin. J Fish Wildl Manag. 2012;3:311-8.

40. Erb LP, Ray C, Guralnick R. On the generality of a climate-mediated shift in the distribution of the American pika (Ochotona princeps). Ecology. 2011;92:1730-5 
41. Beever E, Dobrowski SZ, Long J, Mynsberge AR, Piekielek NB. Understanding relationships among abundance, extirpation, and climate at ecoregional scales. Ecology. 2013;94:1563-71.

42. Millar Cl, Westfall RD, Delany DL. New records of marginal locations for American Pika (Ochotona princeps) in the Western Great Basin. West North Am Nat. 2013;73:457-76.

43. Williams SE, Shoo LP, Isaac JL, Hoffmann AA, Langham G. Towards an integrated framework for assessing the vulnerability of species to climate change. PLoS Biol. 2008;6:2621-6.

44. Huey RB, Kearney MR, Krockenberger A, Holtum JAM, Jess M, Williams SE. Predicting organismal vulnerability to climate warming: roles of behaviour, physiology and adaptation. Philos Trans R Soc Lond B Biol Sci. 2012;367:1665-79.

45. Nicotra AB, Beever EA, Robertson AL, Hofmann GE, O'Leary J. Assessing the components of adaptive capacity to improve conservation and management efforts under global change. Conserv. Biol. 2015;29:1268-78.

46. Dawson TP, Jackson ST, House Jl, Prentice IC, Mace GM. Beyond predictions: biodiversity conservation in a changing climate. Science. 2011;332:53-8.

47. Wise EK. Tree ring record of streamflow and drought in the upper Snake River. Water Resour Res. 2010;46, W11529.

48. Stevens DL, Olsen AR. Variance estimation for spatially balanced samples of environmental resources. Environmetrics. 2003;14:593-610.

49. Rodhouse T, Beever E, Garrett L, Irvine K, Jeffress M, Munts M, et al. Distribution of American pikas in a low-elevation lava landscape: conservation implications from the range periphery. J Mammal. 2010;91:1287-99.

50. Jeffress MR, Rodhouse TJ, Ray C, Wolff S, Epps CW. The idiosyncrasies of place: geographic variation in the climate-distribution relationships of the American pika. Ecol Appl. 2013;23:864-78.

51. Davy E. Existing vegetation mapping summary: Bridger-Teton National Forest. Salt Lake City: US Forest Service; 2007.

52. Stevens DL, Olsen AR. Spatially balanced sampling of natural resources. J Am Stat Assoc. 2004;99:262-78.

53. Stewart JAE, Wright DH. Assessing persistence of the American pika at historic localities in California's Northern Sierra Nevada. Wildl Soc Bull. 2012:36:759-64.

54. Millar C, Heckman K, Swanston C, Schmidt K, Westfall RD, Delany DL. Radiocarbon dating of American pika fecal pellets provides insights into population extirpations and climate refugia. Ecol Appl. 2014;24:1748-68.

55. Hayes AR, Huntly NJ. Effects of wind on the behavior and call transmission of pikas (Ochotona princeps). J Mammal. 2005;86:974-81.

56. Yandow LH, Chalfoun AD, Doak DF. Climate tolerances and habitat requirements jointly shape the elevational distribution of the American pika (Ochotona princeps), with implications for climate change effects. PLoS One. 2015;10:e0131082.

57. Wilkening $J$, Ray C, Beever EA, Brussard PF. Modeling contemporary range retraction in Great Basin pikas (Ochotona princeps) using data on microclimate and microhabitat. Quat Int. 2011;235:77-88.

58. Barrio IC, Hik DS, Bueno CG, Cahill JF. Extending the stress-gradient hypothesis - is competition among animals less common in harsh environments? Oikos. 2013;122:516-23.

59. Elzinga CL, Salzer DW, Willoughby JW. Measuring \& monitoring plant populations. Denver; Bureau of Land Management; 2001.

60. Huntly NJ, Smith AT, Ivins BL. Foraging behavior of the Pika (Ochotona princeps), with comparisons of grazing versus haying. J Mammal. 1986;67:139-48.

61. Huntly NJ. Influence of refuging consumers (Pikas: Ochotona princeps) on subalpine meadow vegetation. Ecology. 1987;68:274-83.

62. Varner J, Dearing MD. Dietary plasticity in pikas as a strategy for atypical resource landscapes. J Mammal. 2014;95:72-81.

63. Wilkening $J$, Ray C, Varner J. Relating sub-surface ice features to physiological stress in a climate sensitive mammal, the American Pika (Ochotona princeps). PLoS One. 2015;10, e0119327.

64. Mackenzie DI, Nichols JD, Royle JA, Pollock KH, Bailey LL, Hines JE. Occupancy estimation and modeling. San Diego: Elsevier, Inc; 2006.

65. Beever E, Brussard P, Berger J. Patterns of apparent extirpation among isolated populations of pikas (Ochotona princeps) in the Great Basin. J Mammal. 2003;84:37-54.

66. Stage AR. An expression for the effect of aspect, slope, and habitat type on tree growth. For Sci. 1976;22:457-60.

67. Steyerberg EW, Harrell FE, Borsboom GJJM, Eijkemans MJC, Vergouwe Y, Habbema JDF. Internal validation of predictive models: Efficiency of some procedures for logistic regression analysis. J Clin Epidemiol. 2001;54:774-81.
68. Merkle JA, Monteith KL, Aikens EO, Hayes MM, Hersey KR, et al. Large herbivores surf waves of green-up during spring. Proc R Soc B. 2016;283:1-8.

69. Burnham KP, Anderson DR. Model Selection and Multimodel Inference. A Practical Information-Theoretic Approach. Second. New York: Springer; 2002.

70. Mazerolle MJ. Model selection and multimodel inference based on (Q)AIC(c). 2013.

71. Hosmer DWJ, Lemeshow S. Applied Logistic Regression. Second. Hoboken: Wiley; 2000.

72. Sing T, Sander O, Beerenwinkel N, Lengauer T. Visualizing the performance of scoring classifiers. 2013.

73. Hinkle DE, Wiersma W, Jurs SG. Applied Statistics for the Behavioral Sciences. 5th ed. Boston: Houghton Mifflin; 2003.

74. R Core Team. R: A language and environment for statistical computing. Vienna: R Foundation for Statistical Computing; 2012.

75. Inouye DW. Effects of climate change on phenology, frost damage, and floral abundance of montane wildflowers. Ecology. 2008;89:353-62.

76. Millar $\mathrm{Cl}$, Westfall RD, Delany DL. Thermal regimes and snowpack relations of periglacial talus slopes, Sierra Nevada, California, U.S.A. Arctic, Antarct Alp Res. 2014;46:483-504

77. Hamel S, Garel M, Festa-Bianchet M, Gaillard J-M, Côté SD. Spring Normalized Difference Vegetation Index (NDVI) predicts annual variation in timing of peak faecal crude protein in mountain ungulates. J Appl Ecol. 2009;46:582-9.

78. Albon SD, Langvatn R. Plant phenology and the benefits of migration in a temperate ungulate. Oikos. 1992;65:502-13.

79. Franken RJ, Hik DS. Influence of habitat quality, patch size and connectivity on colonization and extinction dynamics of collared pikas Ochotona collaris. J Anim Ecol. 2004;73:889-96.

80. Smith AT. Comparative demography of pikas (Ochotona): Effect of spatial and temporal age-specific mortality. Ecology. 1978;59:133-9.

81. Smith AT, Ivins BL. Reproductive tactics of pikas: why have two litters? Can J Zool. 1983;61:1551-9.

82. Fick LG, Kucio TA, Fuller A, Matthee A, Mitchell D. The relative roles of the parasol-like tail and burrow shuttling in thermoregulation of free-ranging Cape ground squirrels, Xerus inauris. Comp Biochem Physiol, Part A. 2009; 152:334-40

83. Henry P, Henry A, Russello MA. Variation in habitat characteristics of American Pikas along an elevation gradient at their northern range margin. Northwest Sci. 2012;86:346-50.

84. MacArthur RA, Wang LCH. Physiology of thermoregulation in the pika. Ochotona princeps Can J Zool. 1973;51:11-6.

85. Angilletta JMJ, Cooper BS, Schuler MS, Boyles JG. The evolution of thermal physiology in endotherms. Front Biosci. 2010;E2:861-81.

86. Erb LP, Ray C, Guralnick R. Determinants of pika population density vs. occupancy in the Southern Rocky Mountains. Ecol. Appl. 2014;24:429-35.

87. Simpson WG. American Pikas inhabit low-elevation sites outside the species' previously described bioclimatic envelope. West North Am Nat. 2009;69:243-50.

88. Dearing $\mathrm{D}$. The manipulation of plant toxins by a food-hoarding herbivore. Ochotona princeps. Ecology. 1997;78:774-81.

89. Welbergen JA, Klose SM, Markus N, Eby P. Climate change and the effects of temperature extremes on Australian flying-foxes. Proc Biol Sci. 2 $008 ; 275: 419-25$

90. Wang G, Dillon ME. Recent geographic convergence in diurnal and annual temperature cycling flattens global thermal profiles. Nat Clim Chang. 2014;4:988-92.

\section{Submit your next manuscript to BioMed Central and we will help you at every step:}

- We accept pre-submission inquiries

- Our selector tool helps you to find the most relevant journal

- We provide round the clock customer support

- Convenient online submission

- Thorough peer review

- Inclusion in PubMed and all major indexing services

- Maximum visibility for your research

Submit your manuscript at www.biomedcentral.com/submit 